a white patient and were more likely to advocate criminal proceedings against the Afro-Caribbean patient. Lewis et al pose the question "Are British psychiatrists racist?" but never give the answer, clear in their own findings, "yes".

B. DOLAN

Section of Forensic Psychiatry

C. Evans

St Georges Hospital Medical School

Tooting

London SW17 ORE

\section{Social order/mental disorder}

SIR: While I was pleased to see a review (Journal, March 1990, 156, 454-455) of my most recent book, Social Order/Mental Disorder (1989), I found much in the review itself with which I would wish to quarrel. I shall not dwell on matters of taste and interpretation, since these are, as Henry Rollin acknowledges, matters on which dispute can be endless. Besides, criticisms of this sort are perfectly legitimate matters for a reviewer to raise. But I do object to having my position misrepresented and caricatured in order to provide the reviewer with a straw man to assault.

I must first take issue with the peculiar notion that it is the historian's duty to preserve the reputation of the "folk heroes of British psychiatry" intact, heedless of what the historical record may show; and without belabouring the point, I think that most people outside the ranks of organised psychiatry would raise an eyebrow or two at the notion that psychiatrists themselves (and psychiatrists alone?) qualify as "historians whose impartiality is unimpeachable". But, more particularly, I must protest at the absurd claim that $I$ argue that the proliferation of 19 th century asylums "was engineered by unscrupulous doctors" - and at the still stranger notion that $I$ am "a staunch advocate of community care" and view the late 18th-century as "the Golden Age for the mentally disordered".

Lunacy reform in the Victorian age was a long and complicated process, in which medical men played a significant but clearly subordinate role. The great importance of other historical factors and actors (including the "redoubtable Earl of Shaftesbury") is scarcely news to me, since I have published a lengthy monograph on the subject (Skull, 1979). No careful or "impartial" reader of either that extended analysis, or of the necessarily more fragmentary discussions of the subject in Social Order/Mental Disorder, would, I submit, recognise Dr Rollin's caricature as a fair representation of my position.
As for "community care", there is something more than slightly ironic about the claim that I am one of its cheerleaders. My Decarceration (Skull, 1977) was one of the first sustained critiques of deinstitutionalisation. In Social Order/Mental Disorder, I return repeatedly to "the appalling deficiencies of yet another generation of "mental health reforms" "; I refer to the "castastrophic failures masquerading under the official guise of a 'revolution' in psychiatric care"; criticise "the odd mixture of zealots and penny-pinching politicians who continue to call malign neglect "community care" "; document that "community care is simply a sham"; and analyse why such an approach nonetheless continues to dominate mental health policies on both sides of the Atlantic. So far from romanticising the 18 th century, I specifically compare the contemporary board and care industry in the United States, which has battened upon the legions of discharged mental patients, with the horrors of the late 18th-century English madhouses or "trade in lunacy". I call attention to "our collective reluctance to make a serious and sustained effort to provide a humane and caring environment for those manifesting grave and persistent mental disturbance"; and, dare I say it, I protest "the retreat even of organised psychiatry from any attempt to deal with their problems".

Dr Rollin's bee in his bonnet about sociologists who work on the history of psychiatry has evidently precluded him from reading what I actually have to say. We have plenty of real issues to debate, for I am far from being a complacent or uncritical observer of the psychiatric scene, past or present. But it would help if we could argue about matters of substance, rather than engaging in disciplinary demonology.

\section{Department of Sociology}

University of California

La Jolla, California 92093

\section{ANDREW SKULL}

\section{References}

SkuLL, A. (1977) Decarceration (2nd edn.). Englewood Cliffs, New Jersey: Prentice-Hall/Oxford: Polity Press.

(1979) Museums of Madness. London: Allen Lane. - (1989) Social Order/Mental Disorder. London: Routledge.

\section{Treatment of depression with pumpkin seeds}

SIR: I suspect that many colleagues may have shared my experience of patients who were previously maintained on L-tryptophan but have suffered partial or complete relapse since its withdrawal from the market earlier this year. I report on one such case and his successful treatment with pumpkin seeds. 
Case report: A 44-year-old man of Polish descent first presented to the psychiatric services in 1982 with recurrent unipolar depressions. His subsequent treatment was complicated by his suffering significant side-effects on most first-line antidepressants. Those that he was able to tolerate (e.g. low-dose clomipramine) tended to induce hypomania after a few weeks of treatment. It was in some desperation, therefore, that I put him on L-tryptophan in 1985. Such was his apparent sensitivity to psychotropic medication that he became hypomanic on $4.5 \mathrm{~g}$ of L-tryptophan per day. During the next few months he became very stable on $1.5 \mathrm{~g}$ of L-tryptophan per day and he was discharged from follow-up in July 1985.

He was referred back by his general practitioner this August. It seems that he had remained entirely well over the five years previous to this, apart from a bout of depression with biological features every three months or so. At these points he took about $1.5 \mathrm{~g}$ of L-tryptophan over two days and found that this quickly restored his well being. When he was referred back to me he had been constantly depressed for three months with anergia, early-morning wakening, loss of appetite and anhedonia.

Another patient (a medical practitioner) who had suffered sleep disturbance on withdrawing from the L-tryptophan on which she had been maintained, had researched the topic and established that pumpkin seeds were the most costeffective means of administering natural L-tryptophan: a typical $250 \mathrm{~g}$ bag contains $1300 \mathrm{mg}$ and costs about $£ 1.00$.

Within 24 hours of ingesting about 200 grams of pumpkin seeds (i.e. about 1 gram of L-tryptophan), the patient felt quite transformed. He was no longer anergic or depressed and happily returned to work the following day.

Clearly this patient is atypical in that his mood state appears to be remarkably sensitive to L-tryptophan. However, for patients who were successfully maintained on L-tryptophan or for whom one wishes to instigate L-tryptophan, pumpkin seeds may represent the best alternative at present. Perhaps, as in this case, the biggest hurdle is overcoming the scepticism of one's patient!

\section{The Ross Clinic \\ Cornhill Road}

Aberdeen $A B 92 Z F$

JOHN M. EAGLES

\section{Down's syndrome, dementia and myoclonic jerks}

SIR: The recent publicity surrounding bovine spongiform encephalopathy (BSE) has intensified the search for cases of the human concomitant, Creuzfeldt Jakob disease. The combination of a dementing process and myoclonic jerks in a person under the age of 70 years raises suspicions of such a diagnosis. I urge for caution before reaching this conclusion.

There are two accounts in the literature of a combination of Down's syndrome, dementia and myoclonus (Blumbergs et al, 1981; Good \& Howard, 1982).
Both were originally presumed to be Creuzfeldt Jakob disease but post-mortem findings indicated Alzheimer's disease which commonly occurs prematurely in people with Down's syndrome. Faden \& Townsend (1976) draw attention to the confusion arising when myoclonus occurs in association with dementia, and assert that this should not be considered pathognomonic of Creuzfeldt Jakob disease and that a diagnosis of Alzheimer's disease should be considered. This difficult diagnostic problem is illustrated by the following case.

Case report: $A$ is a 48-year-old single lady with Down's syndrome. She developed grand mal epilepsy three years ago and an electroencephalogram (EEG) at that time showed no evidence of a space-occupying lesion. She was successfully treated with phenytoin and seizures are now infrequent.

For the last 18 months there has been a steady deterioration in her memory and she is now unable to recognise close family members. Her speech has deteriorated and she spends much of her time muttering to herself. Her self-care has deteriorated and she has become doubly incontinent, necessitating full nursing care. Her motivation is poor and her mood is labile. One year ago she developed myoclonic jerks. These occur only 1-2 hours after waking and affect her head, arms, shoulders, body and legs. They are abrupt, brief, irregular, asymmetrical and can be so severe as to catapult her out of her wheelchair.

A repeat EEG shows generalised irregular 3-7 Hz slow activity, with no change from her EEG of 1987 . In particular, there is no evidence of periodic biphasic or triphasic complexes characteristic of Creuzfeldt Jakob disease.

In the light of the experience of other authors, the time course of the clinical findings and the lack of specific abnormalities on the EEG of this patient, the diagnosis should be Alzheimer's disease until proven otherwise.

\section{UMDS Section of Psychiatry \\ Guy's Hospital \\ London Bridge \\ London SEI 9RT}

AdRIAN J. B. JAMES

\section{References}

Blumbergs, P., Beran, R. \& Hicks, P. (1981) Myoclonus in Down's syndrome: associated with Alzheimer's disease. Archives of Neurology, 38, 453-454.

FADEN, P. \& TOWNSEND, J. (1976) Myoclonus in Alzheimer's disease: a confusing sign. Archives of Neurology, 33, 278-280.

GOOD, D. \& HowARD, H. (1982) Myoclonus in Down's syndrome: treatment with clonazepam (letter). Archives of Neurology, 39, 195.

\section{How informed and binding is informed consent?}

SIR: We report a case in which the patient's consent for an interview with him to be broadcast, given while he was well, had an affect on his mental state. 